\title{
Oxidative Damage in Rats Receiving Ethanol and Supplemented with Vitamin E
}

\author{
Alceu Afonso Jordao ${ }^{1}$, Thais Helena Monteiro ${ }^{1}$, Raquel Alves dos Santos ${ }^{2}$, \\ Guilherme Vannucchi Portari ${ }^{3}$ \\ ${ }^{1}$ Division of Nutrition, Department of Internal Medicine, Medical School of Ribeirão Preto, University of São Paulo, Ribeirão Preto, Brazil \\ ${ }^{2}$ Nucleus of Research in Sciences and Technology, University of Franca, Franca, Brazil \\ ${ }^{3}$ Department of Nutrition, Federal University of Triangulo Mineiro, Uberaba, Brazil
}

Email address:

alceu@fmrp.usp.br (A. A. Jordao)

\section{To cite this article:}

Alceu Afonso Jordao, Thais Helena Monteiro, Raquel Alves dos Santos, Guilherme Vannucchi Portari. Oxidative Damage in Rats Receiving Ethanol and Supplemented with Vitamin E. American Journal of Biomedical and Life Sciences. Vol. 2, No. 3, 2017 , pp. 88-91.

doi: 10.11648/j.ajbls.20170505.11

Received: April 11, 2017; Accepted: May 23, 2017; Published: October 18, 2017

\begin{abstract}
The metabolism of ethanol is directly related to oxidative stress, and its ingestion leads to the formation of reactive oxygen species (ROS) such as hydroxyl radicals, superoxide and hydrogen peroxide. Vitamin E has been widely used as an antioxidant; when administered in large doses it is deposited in the liver and then excreted in the bile, urine and feces. The objective of the present study was to evaluate the rate of excretion of fecal vitamin $E$ in relation to its concentrations in serum and liver, and its role as a protective antioxidant against DNA damage induced by acute ethanol consumption. Wistar rats were divided into four groups receiving food and water ad libitum for 4 days plus the following treatments: Control (CG, $\mathrm{n}$ $=10$ ) no treatment; Ethanol (ET, $\mathrm{n}=10$ ), receiving an acute ethanol dose intraperitoneally in the amount of $5 \mathrm{~g} / \mathrm{kg}$; vitamin $\mathrm{E}$ $(\mathrm{VE}, \mathrm{n}=10)$ receiving a high oral dose of vitamin $\mathrm{E}$ within the first three days in the amount of 100 tocopherol $\mathrm{mg} / \mathrm{kg}$ body weight; ethanol plus vitamin $\mathrm{E}(\mathrm{VE}+\mathrm{ET}, \mathrm{n}=10$ ) receiving both the ethanol and vitamin $\mathrm{E}$ doses. Higher concentrations of vitamin $\mathrm{E}$ were observed in the blood and liver of the animals in the groups that received vitamin $\mathrm{E}$ supplementation, independent of the presence or absence of ethanol. Concomitantly, these groups were also those with the highest concentration of the vitamin in the stool. The rate of DNA damage was higher in the groups that received ethanol with or without supplemental vitamin E. However, the rate of damage was lower in the group that received vitamin E supplementation than in the group that did not. The present results show that vitamin $\mathrm{E}$ has a protective effect against DNA damage induced by ethanol by reducing the extent of DNA damage.
\end{abstract}

Keywords: Vitamin E, Ethanol, Antioxidants, DNA Damage, Supplementation

\section{Introduction}

Ethanol metabolism is directly related to oxidative stress, In the organism, about 2 to $10 \%$ of the absorbed ethanol is eliminated through the kidneys and lungs and the remainder is practically metabolized in hepatic tissue $[1,2]$, since it cannot be stored, in a process involving two phases. In the first, ethanol is oxidized to acetaldehyde through three possible pathways, i.e., alcohol dehydrogenase (ADH) in the cytosol, microsomal ethanol oxidizing system (MEOS) in the endoplasmic reticulum, or catalase in the peroxysomes. In the second phase, acetyl-CoA and acetate are formed from acetaldehyde oxidation by aldehyde dehydrogenase, this representing an irreversible transformation [3]. This oxidative pathway of ethanol metabolism favors a high formation of reactive oxygen species (ROS) such as hydroxyl radicals, superoxide and hydrogen peroxide. These, by being highly unstable, may initiate tissue damage by reacting with other molecules such as lipids, favoring increased lipid peroxidation and generating toxic final products such as malondialdehyde and by reacting with cell proteins, forming complexes that act as autoantigens triggering the immune response [4] and inducing DNA damage [5]. Ethanol has no genotoxic effect per se, but its oxidation to acetaldehyde is 
related to a single break, i.e., a break in one of the two DNA chains [6]. Acetaldehyde has a genotoxic effect through various mechanisms such as ROS generation [7] crosslinking of proteins to DNA [8] and the formation of DNA and nucleoside adducts [9] The organism has antioxidant defense mechanisms that protect cell structures against the damage provoked by ROS, which may be endogenous like thiols such as glutathione and the enzymes glutathione peroxidase, catalase and superoxide dismutase, or exogenous, such as tocopherol, carotenoids, ascorbic acid and flavonoids from the diet [10].

Vitamin $\mathrm{E}$ is present in large amounts in lipids, playing a strong protective antioxidant role against lipid peroxidation of cell membrane polyunsaturated fatty acids. Vitamin E belongs to a group of eight naturally occurring homologous compounds, the tocopherols (TOH) and the tocotrienols, both in the $\alpha-, \beta-, \gamma$ - and $\delta$ - forms. Alpha-Tocopherol $(\alpha-\mathrm{TOH})$ is the most bioactive in the organism and is considered to be the most potent antioxidant of the liposoluble type [12].

In a study by our group [13] vitamin E supplementation increased the serum and hepatic concentrations of the vitamin in rats, but the hepatic store of the vitamin was reduced 2 hours after acute ethanol administration in the group receiving a vitamin E-deficient diet, after 8 hours in the group receiving a normal diet, and after 24 hours in the group receiving a diet supplemented with vitamin E. In particular, recovery of vitamin E stores occurred during the subsequent period in the animals receiving a normal diet.

Vitamin $\mathrm{E}$ is excreted through the bile, urine and feces [14], although vitamin E is liposoluble, Jordão Jr et al [15] detected urinary vitamin $\mathrm{E}$ excretion in healthy individuals and in subjects with HIV infection and AIDS, with the last group showing the highest vitamin concentration in urine. In rats, the plasma concentration of $\alpha-\mathrm{TOH}$ ranges from 7.2 to $13.0 \mu \mathrm{mol} / \mathrm{L}$, and is higher than the concentration of $\gamma-\mathrm{TOH}$, which ranges from 1.3 to $1.7 \mu \mathrm{mol} / \mathrm{L}$. The hepatic store is also greater for the $\alpha$ isoform compared to the $\gamma$ form, with respective concentrations ranging from 30.0 to $33.4 \mathrm{nmol} / \mathrm{g}$ and from 4.5 a $5.3 \mathrm{nmol} / \mathrm{g}$ [16].

The objective of the present study was to determine the rate of vitamin $\mathrm{E}$ excretion through the feces in relation to its serum and hepatic concentrations, and the protective antioxidant role of the vitamin against the cytogenotoxicity induced by acute ethanol consumption.

\section{Methodology}

Male Wistar rats weighing between 150 - 180g were obtained from the Central Animal Facilities of the Faculty of Medicine of Ribeirão Preto - USP. The animals were alocated into four groups receiving commercial diet for rodents (Nuvilab CR-1, Nuvital Nutrientes S/A, Brazil) and water ad libitum for 4 days, plus the following treatments: Control $(\mathrm{C})(\mathrm{n}=10)$, received saline solution by gavages for 3 days; Ethanol $(\mathrm{ET})(\mathrm{n}=10)$ received saline solution for 2 days and on the $3 \mathrm{rd}$ day received an acute dose of ethanol per gavage in the amount of $5 \mathrm{~g} / \mathrm{kg}$ body weight; Vitamin $\mathrm{E}$
(VE) $(\mathrm{n}=10)$, received tocopheryl acetate by gavage at the dose of $100 \mathrm{mg} / \mathrm{kg}$ of weight for 3 days; Ethanol + Vitamin $\mathrm{E}(\mathrm{ET}+\mathrm{VE})(\mathrm{n}=10)$ received tocopherol acetate by gavage at a dose of $100 \mathrm{mg} / \mathrm{kg}$ of weight for 3 days and ethanol (dose of $5 / \mathrm{kg}$ ) on the 3 rd day 30 minutes after gavage of vitamin $\mathrm{E}$. The animals were housed in individual cages on a 12 hour light-dark cycle at a mean room temperature of $22^{\circ} \mathrm{C}$. Food intake was controlled by weighing the feeders and the animals were weighed at the end of the experiment, without differences between the groups. The feces were collected from all groups in the last day of experiment and samples contaminated with hair or ration were discarded. All animals were euthanized by decapitation 6 hours after the last gavage, blood was collected for the determination of plasma vitamin $\mathrm{E}$, and the liver was removed, weighed and immediately placed in liquid nitrogen $\left(-196^{\circ} \mathrm{C}\right)$ for later determination of vitamin $\mathrm{E}$. The comet assay was carried out using fresh samples of the right lobe of the liver.

For the determination of vitamin E, a $1 \mathrm{~mL}$ serum aliquot and a $200 \mathrm{mg}$ liver mass and stool mass were obtained and homogenized in $2 \mathrm{~mL}$ ethanol. Next, the mixture was added to $2 \mathrm{~mL}$-hexane, shaken for 2 minutes and centrifuged at $1,000 \mathrm{rpm}$ for 10 minutes. The supernatant, $1 \mathrm{~mL}$-hexane, was extracted and carefully dried under gaseous nitrogen flux The sample obtained was suspended again in $0.5 \mathrm{~mL}$ of the mobile phase consisting of acetonitrile, dichloromethanol and methanol (70:20:10, v. v. v.), and $100 \mu \mathrm{L}$ of the sample were used for analysis. The concentration of $\alpha-\mathrm{TOH}$ was estimated by HPLC using a Shimadzu apparatus model LC-10 AT, a 4.6 $\mathrm{mm}$ by $25 \mathrm{x} \mathrm{cm} \mathrm{C18} \mathrm{column,} \mathrm{a} \mathrm{flow} \mathrm{of} 1.5 \mathrm{~mL} / \mathrm{min}, \mathrm{UV} / \mathrm{Vis}$ of $292 \mathrm{~nm}$, a particle diameter of $5.0 \mu \mathrm{m}$, and an injection volume of $20 \mu \mathrm{L}$. The apparatus was calibrated with standard solutions of $\alpha$-tocopherol at concentrations of 10, 20 and 200 $\mu \mathrm{mol} / \mathrm{L}$. Data were obtained by comparison and are reported as $\mu \mathrm{mol} / \mathrm{L}$ or $\mu \mathrm{mol} / \mathrm{g}$.

\section{Comet Assay}

An aliquot of $300 \mu \mathrm{L}$ was taken from each cell sample after the procedure of mincing liver tissue in Hanks solution ( $1 \%$ DMSO) to test for cell viability by trypan blue exclusion and for the alkaline version of the Comet assay as described (6). Briefly, $300 \mu \mathrm{L}$ of the cell suspension was centrifuged for 5 minutes $(500 \mathrm{rpm})$ in a refrigerated microcentrifuge (Eppendorff). The resulting pellet was homogenized with 80 $\mu \mathrm{L}$ of a low melting point agarose $(0.5 \%)$, spread onto microscope slides pre-coated with a normal melting point agarose $(1.5 \%)$, and covered with a coverslip. After $5 \mathrm{~min}$ at $4^{\circ} \mathrm{C}$, the coverslip was removed and the slides were immersed in cold lysis solution $(2.4 \mathrm{M} \mathrm{NaCl} ; 100 \mathrm{mM}$ EDTA; $10 \mathrm{mM}$ Tris, $10 \%$ DMSO and 1\% Triton-X, $\mathrm{pH} 10$ ) for 24 hours. After lysis, the slides were placed in an electrophoresis chamber and covered with electrophoresis buffer $(300 \mathrm{mM} \mathrm{NaOH}$ per $1 \mathrm{mM}$ EDTA, $\mathrm{pH}>13)$, for an additional $20 \mathrm{~min}$ to permit DNA unwinding. The electrophoresis proceeded for $20 \mathrm{~min}(25 \mathrm{~V}$ and $300 \mathrm{~mA})$ and the slides were then submerged for $15 \mathrm{~min}$ in neutralization 
buffer (0.4 M Tris- $\mathrm{HCl}, \mathrm{pH} 7.5)$, dried at room temperature and fixed in $100 \%$ ethanol for $5 \mathrm{~min}$. Slide staining was performed immediately before analysis using ethidium bromide $(20 \mu \mathrm{g} / \mathrm{mL})$. Slides were prepared in duplicate and 100 cells were screened per sample (50 cells from each slide) under a fluorescent microscope (ZEISS, Germany) equipped with an excitation filter of 515-560 nm and a barrier filter of $590 \mathrm{~nm}$ using a $40 \mathrm{X}$ objective. The nucleus was classified visually according to the migration of the fragments as: class 0 (no damage); class 1 (little damage with a short tail length smaller than the diameter of the nucleus); class 2 (medium damage with a tail length one or two times the diameter of the nucleus); class 3 (significant damage with a tail length between two and a half to three times the diameter of the nucleus); class 4 (significant damage with a long tail of damage greater than three times the diameter of the nucleus).

The data of the comet assay were compared by analysis of variance (ANOVA) with the level of significance set at $\alpha=0.05$.

\section{Results}

Vitamin E concentrations in serum, liver and feces of all groups are showed in Table 1.

Table 1. Vitamin E concentration in the serum, liver and feces of the different groups.

\begin{tabular}{llll}
\hline Group & $\begin{array}{l}\text { Serum } \\
(\mu \mathrm{mol} / \mathbf{L})\end{array}$ & Liver $(\boldsymbol{\mu m o l} / \mathbf{g})$ & Feces $(\boldsymbol{\mu m o l} / \mathbf{g})$ \\
\hline Control $(\mathrm{C})$ & $7.32 \pm 1.56$ & $14.63 \pm 2.90$ & $70.63 \pm 19.58$ \\
Ethanol (ET) & $4.91 \pm 2.05$ & $19.48 \pm 4.68$ & $86.57 \pm 15.89$ \\
Vit E (VE) & $24.31 \pm 4.10^{\mathrm{a}, \mathrm{b}}$ & $94.18 \pm 32.01^{\mathrm{a}, \mathrm{b}}$ & $309.70 \pm 232.88^{\mathrm{a}, \mathrm{b}}$ \\
ET + VE & $19.22 \pm 7.11^{\mathrm{a}, \mathrm{b}}$ & $82.03 \pm 34.87^{\mathrm{a}, \mathrm{b}}$ & $246.86 \pm 68.14^{\mathrm{a}}$ \\
\hline
\end{tabular}

${ }^{\mathrm{a}}: \mathrm{p}<0.05$ compared to $\mathrm{C}$; ${ }^{\mathrm{b}}: \mathrm{p}<0.05$ compared to ET. C: control; ET: ethanol; VE: vitamin E; VE + ET: vitamin E plus ethanol.

In serum, higher vitamin $\mathrm{E}$ concentrations were observed in the VE group, being approximately 3.3 times higher than in the $\mathrm{C}$ group and 4.9 times higher than in the ET group, and being 2.6 times higher in the ET + VE group than in the $\mathrm{C}$ group and 3.9 times higher than in the ET group. A similar behavior was observed in the liver. The concentrations in the VE group were 6.4 times higher than in the $\mathrm{C}$ group and 4.8 times higher than in the ET group, and in the ET + VE group they were 5.6 times higher than in the $\mathrm{C}$ group and 4.2 times higher than in the ET group.

A similar behavior was observed in the feces. The highest concentrations were detected in the VE group, being 4.4 times higher than in the $\mathrm{C}$ group and 3.6 times higher than in the ET group, and being 3.5 times higher in the ET $+\mathrm{VE}$ group than in the $\mathrm{C}$ group.

DNA damage was observed with the aid of the comet assay and the results are listed in Table 2.

It can be seen that both the comet frequency and the rate of DNA damage were significantly higher in the ET and EE groups compared to control $(p<0.01)$. However, it can be seen that the EE group showed a significantly lower rate of
DNA damage than the ET group ET $(\mathrm{p}<0.01)$

Table 2. Comet cells (CC) and DNA damage index (DI) obtained in liver samples from Wistar rats submitted to different treatments with VE and/or ethanol.

\begin{tabular}{|c|c|c|c|c|c|c|c|}
\hline \multirow{2}{*}{ Group } & \multicolumn{5}{|c|}{ Comet Length } & \multirow{2}{*}{$\begin{array}{l}\text { CC Mean } \\
\pm \text { SD }\end{array}$} & \multirow{2}{*}{ DI Mean \pm SD } \\
\hline & $\mathbf{0}$ & 1 & 2 & 3 & 4 & & \\
\hline $\mathrm{C}$ & 834 & 105 & 38 & 14 & 9 & $16.6 \pm 2.4$ & $25.9 \pm 5.7$ \\
\hline ET & 634 & 141 & 102 & 92 & 31 & $36.6 \pm 4.2^{\mathrm{a}}$ & $74.5 \pm 9.6^{\mathrm{a}}$ \\
\hline VE & 836 & 76 & 55 & 20 & 13 & $16.3 \pm 4.2$ & $29.8 \pm 7.1$ \\
\hline $\mathrm{ET}+\mathrm{VE}$ & 676 & 129 & 134 & 39 & 22 & $32.4 \pm 3.1^{\mathrm{a}}$ & $60.2 \pm 5.6^{\mathrm{a}, \mathrm{b}, \mathrm{c}}$ \\
\hline
\end{tabular}

${ }^{\mathrm{a}}: \mathrm{p}<0.05$ compared to $\mathrm{C} ;{ }^{\mathrm{b}}: \mathrm{p}<0.05$ compared to ET; ${ }^{\mathrm{c}}: \mathrm{p}<0.05$ compared to VE. C: control; ET: ethanol; VE: vitamin E; VE + ET: vitamin E plus ethanol.

\section{Discussion}

In the present study, higher vitamin E concentrations were observed in the blood and liver of the animals receiving vitamin E supplementation both in the presence and absence of ethanol. Concomitantly, these groups also showed the highest concentration of the vitamin in the feces. Thus, we may infer that greater vitamin intake can increase the hepatic store and plasma concentration to a maximum threshold, beyond which the vitamin cannot be utilized and the excess is excreted.

The values of vitamin $\mathrm{E}$ in blood observed in the present study confirms the fact that vitamin E supplementation is unable to increase the plasma concentration of the vitamin by more than 2 to 4 times the normal concentration because, by being a fat-soluble vitamin, it requires a specific protein for transport, the $\alpha$-TOH transporter protein ( $\alpha$-TTP), a fact that limits the amount of incorporation of the vitamin into VLDL lipoproteins for transport in the blood circulation [17].

The rate of DNA damage was higher in the two groups receiving ethanol, whether or not accompanied by vitamin $\mathrm{E}$ supplementation. However, the supplemented group showed a lower rate of damage than the group that was not supplemented. Thus, the reduction of the DNA damage mediated by vitamin E supplementation is minimal since this group still showed significant DNA damage compared to the negative control. Other studies also demonstrated that antioxidant agents can prevent or even reverse induced DNA damage [18]. It was demonstrated that derivatives of selenium, an element with an extensively studied antioxidant action, were able to prevent the oxidative damage induced by the chemotherapeutic drug doxorubicin [18]. Moreover, in a model of chronic alcoholism, the level of DNA damage detected as chromosomal aberrations is increased in the group of animals that received ethanol [19].

Vitamin $\mathrm{E}$ is a potent antioxidant and has been demonstrated to be able to prevent or even reverse the oxidative damage induced by drugs. Experimental treatment with ethanol diet induces oxidative stress and consequent liver toxicity, independent of the levels of fat in diet, and that tocopherol supplementation has a protective effect against oxidative stress and liver toxicity in rats [20]. Shirpoor et al. 
[21] demonstrated that treatment with vitamin E induces a significant amelioration of brain atrophy and DNA damage in the offspring of female Wistar rats that received ethanol during gestation and seven days of lactation. A recent metaanalysis showed that vitamin E significantly improved liver function and histologic changes in patients with hepatic steatosis [22]. Ozkol et all showed relative protection against acute EtOH toxicity, in both single and combined pretreatments of Selenium, N-Acetylcysteine, and Vit E supplementation were seen in brain, liver, and kidney tissues, probably by antioxidant mechanism [23].

Interestingly, in the present study vitamin E was excreted through the feces in both the VE and the EE groups, thus indicating that the maintenance of plasma and hepatic levels were not sufficient to reduce the DNA damage to levels comparable to those of the control group.

\section{Conclusion}

We may also conclude that vitamin $\mathrm{E}$ had a chemopreventive role regarding the DNA damage induced by ethanol, although this effect was not antigenotoxic. The results show that vitamin $\mathrm{E}$ had a protective effect against the DNA damage induced by ethanol, reducing the extent of DNA damage. More studies with different doses and duration should be performed to elucidate the metabolism of vitamin $\mathrm{E}$ and ethanol when given together, and the effects on DNA damage.

\section{References}

[1] Das SK \& Vasudevan DM. Alcohol-induced oxidative stress. Life Sciences 2007; 81: 177-87.

[2] Lieber CS. Ethanol, metabolism, cirrhosis and alcoholism. Clin Chim Acta 1997; 257: 59-84.

[3] Lieber CS. Metabolism of alcohol. Clinics in Liver Disease 2005; 9: 1-35.

[4] Song BJ \& Cederbaum AI. Ethanol-inducible cytochrome P450 (CYP4502E1): biochemistry, molecular biology and clinical relevance: 1996 update. Alcohol Clin Exp Res 1996; 20: 138A-46A.

[5] Brooks PJ. DNA damage, DNA repair, and alcohol toxicity: a review. Alcohol Clin Exp Res 1997; 21: 1073-82.

[6] Singh NP, Khan A. Acetaldehyde: genotoxicity and cytotoxicity in human lymphocytes. Mutat Res 1995; 337: 917.

[7] Nordmann R, Ribiere C, Rouach H. Implication of free radical mechanism of ethanol-induced cellular injury. Free Radical Biol Med 1992; 12: 219-40.

[8] Kuykendall JR, Bogdanffy M. Reaction kinetics of DNAhistone crosslinking by vinyl acetate and acetaldehyde. Carcinogenesis 1992; 13: 2095-2100.
[9] Baraona E, Liu W, Ma XL, Svegliati-Baroni G, Lieber CS. Acetaldehyde-collagen addcuts in N-nitrosodimethylamineinduced liver cirrhosis in rats. Life Sci 1993; 52: 1249-55.

[10] McDonough KH. Antioxidant nutrients and alcohol. Toxicology 2003; 189: 89-97.

[11] Jordão Jr AA, Meirelles MSS, Chiarello PG, Vannucchi H. Efeito da administração crônica de etanol sobre a peroxidação lipídica em ratos. Medicina Ribeirão Preto 2002; 35: 48-52.

[12] Traber MG \& Atkinson J. Vitamin E, antioxidant and nothing more. Free Radic Biol Med 2007; 43 (1): 4-15.

[13] Jordão Jr AA, Chiarello PG, Arantes MR, Meirelles MS, Vannucchi H. Effect of an acute dose of ethanol on lipid peroxidation in rats: action of vitamin E. Food and Chemical Toxicology 2004; 42: 459-64.

[14] Lauzon DA, Johnston SL, Southern LL, Xut Z. The effect of carrier for vitamin $E$ on liver concentrations of vitamin $E$ and vitamin $\mathrm{E}$ excretion in broilers. Metabolism and Nutrition 2008; 87: 934-9.

[15] Jordão Jr AA, Silveira S, Figueiredo JFC, Vannucchi H. Urinary excretion and plasma vitamin E levels in patients with AIDS. Nutrition 1998; 14: 423-6.

[16] Clarke MW, Burnett JR, Croft KD. Vitamin E in human health and disease. Critical Reviews in Clinical Laboratory Sciences 2008; 45(5): 417-50.

[17] Kayden HJ \& Traber MG. Absorption, lipoprotein transport, and regulation of plasma concentrations of vitamin $\mathrm{E}$ in humans. Journal of Lipid Research 1993; 34: 343-58.

[18] Santos RA, Jordao Junior AA, Vannucchi H, Takahashi CS. Protection of doxorubicin-induced DNA damage by sodium selenite and selenomethionine in Wistar rats. Nutrition Research (Los Angeles), v. 27, p. 343-348, 2007.

[19] Tavares DC, Cecchi AO, Jordão Jr AA, Vannucchi H, Takahashi CS. Cytogenetic study of chronic ethanol consumption in rats. Teratogenesis, Carcinogenesis, and Mutagenesis 2001; 21: 361-8.

[20] Lee SJ, Kim SY, Min H. Effects of vitamin C and E supplementation on oxidative stress and liver toxicity in rats fed a low-fat ethanol diet. Nutr Res Pract. 2013; 7: 109-114.

[21] Shirpoor A1, Salami S, Khadem-Ansari MH, Minassian S, Yegiazarian M. Protective effect of vitamin E against ethanolinduced hyperhomocysteinemia, DNA damage, and atrophy in the developing male rat brain. Alcohol Clin Exp Res. 2009; 33 (7): 1181-6.

[22] Sato K, Gosho M, Yamamoto T, Kobayashi Y, Ishii N, Ohashi T, Nakade Y, Ito K, Fukuzawa Y, Yoneda M. Vitamin E has a beneficial effect on nonalcoholic fatty liver disease: a metaanalysis of randomized controlled trials. Nutrition. 2015; 31 (7-8): 923-30.

[23] Ozkol H, Bulut G, Balahoroglu R, Tuluce Y, Ozkol HU. Protective effects of selenium, N-acetylcysteine and Vitamin E against acute ethanol intoxication in rats. Biol Trace Elem Res. 2017; 175 (1): 177-185. 